\title{
Density Functional Theory Analysis of Electronic Structure Variations across the Orthoquinone/Semiquinone/Catechol Redox Series
}

\author{
Daniel E. Wheeler, Jorge H. Rodriguez, and James K. McCusker* \\ Department of Chemistry, University of California at Berkeley, Berkeley, California 94720-1460
}

Received: January 12, 1999; In Final Form: March 12, 1999

\begin{abstract}
The electronic structures of the three oxidation states of the "noninnocent" ligand 3,6-di-tert-butylorthoquinone (3,6-DTBQ) have been studied by nonlocal gradient-corrected density functional theory. Optimized structures obtained at the B3LYP/6-31G* and BLYP/6-31G* levels show that neutral 3,6-DTBQ has two equivalent $\mathrm{C}-\mathrm{O}$ double bonds and a nonaromatic six-membered carbon ring. Upon one- and two- electron reduction to its semiquinone (3,6-DTBSQ) and catechol (3,6-DTBCat) oxidation states, respectively, the single bonds of the ligand become shorter whereas its double bonds elongate. The carbon ring of catechol acquires nearly aromatic character perturbed by a long $\mathrm{C} 1-\mathrm{C} 2$ bond. The calculations confirm that 3,6-DTBQ and 3,6DTBCat have closed-shell configurations and singlet ground states whereas the 3,6-DTBSQ has an openshell configuration and a doublet ground state. Analogous calculations have also been carried out on the 3,5-di-tert-butylsemiquinone (3,5-DTBSQ) isomer. Single point calculations at the U-B3LYP/6-311G** level show that both semiquinone isomers have smaller negative charge densities at the carbons bonded to their tert-butyl groups relative to other carbons of their six-membered rings. The spin densities of both semiquinone isomers are mainly localized at their oxygens with somewhat different delocalization patterns throughout the six-membered ring. Detailed descriptions of the composition of frontier molecular orbitals are given that reveal subtle differences between charge distributions and molecular orbital energies across the orthoquinone/ semiquinone/catechol redox series. Finally, optimized geometric parameters for the closely related molecule 1,2-benzoquinone have been obtained and compared with its X-ray structure to assess possible discrepancies between experimental and theoretical methods.
\end{abstract}

\section{Introduction}

Quinones are an important class of molecules in many disciplines ranging from biophysics to organic chemistry. ${ }^{1}$ The main focus of research has been on derivatives of $p$-quinone (i.e. 1,4-benzoquinone) due to their roles as electron acceptors in photosynthetic assemblies as well as their presence in a large number of enzymes and proteins..$^{2-5}$ Computational studies on these systems have included comparisons of quinones and semiquinones, ${ }^{6-14}$ model plastoquinones, ${ }^{15}$ vibrational analyses, ${ }^{16-22}$ hyperfine splittings, ${ }^{21,23,24}$ and the effects of hydrogen bonding on physical properties such as redox potentials. ${ }^{25-27}$

In contrast to $p$-quinones, $o$-quinones (i.e. 1,2-benzoquinone) have received far less attention. Although $o$-quinones are not as widespread in biological systems as $p$-quinones, they play a much larger role as ligands in transition metal chemistry. Much of the interest in these molecules stems from their redox activity, providing access to three different oxidation states of the molecule:

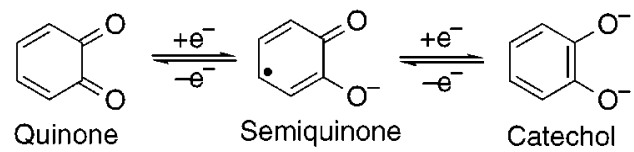

While the quinone form of the molecule does not readily bind to transition metals, there are many examples of semiquinones and catechols forming stable complexes with first, second, and third row transition metals. Over the past two decades, the study of transition metal complexes containing quinones has developed into an active area of research. ${ }^{28-30}$
Recent advances in computational methodology have made it possible to begin applying high-level theory to the study of the electronic structure of transition metal complexes. Transition metal-quinoid compounds are proving to be quite interesting in this regard. In particular, these studies have been successful in determining possible pathways for magnetic exchange between the open-shell metal centers and the paramagnetic $o$-semiquinone ligand. We have recently reported such a study, ${ }^{31}$ in which nonlocal gradient-corrected density functional theory was used to analyze the electronic structure of $[\mathrm{Cr}(\operatorname{tren})(3,6-$ DTBSQ) $]^{2+}$ (where 3,6-DTBSQ is 3,6-di-tert-butylorthosemiquinone and tren is tris(2-aminoethyl)amine), as well as its catecholate analogue $[\mathrm{Cr}(\operatorname{tren})(3,6-\mathrm{DTBCat})]^{+}$. Theoretical studies have also been successful in assigning the electronic transitions seen in valence tautomeric complexes, ${ }^{32}$ as well as the role of diamagnetic metals as media for ligand-ligand exchange. ${ }^{33}$

While a picture is beginning to emerge from these studies concerning the nature of the interactions between metals and bound quinoidal ligands, there have been only a few theoretical studies of the free ligands themselves. Fenske-Hall calculations have been reported on the free quinone ligand for inclusion in a study of the bonding present in metal-quinone complexes. ${ }^{34}$ These authors gave an overview of the molecular orbitals of the quinone; however, no comparison is made between the three oxidation states of the ligand. Bianchini et al. ${ }^{35}$ performed extended Hückel and fragment molecular orbital calculations on the unsubstituted quinone for a study involving $\mathrm{Co}$-quinoid complexes. These authors presented mainly qualitative results 


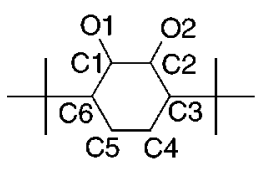

(a)

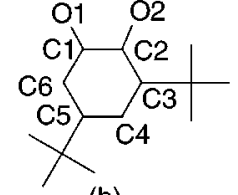

(b)

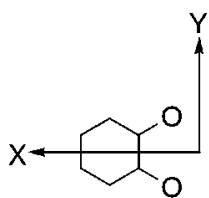

Figure 1. Labeling scheme used for (a) 3,6-di-tert-butylorthoquinoids and (b) 3,5-di-tert-butylorthoquinoids. The coordinate system used as reference for the molecular orbitals is indicated below. Unsaturation in the molecules has been omitted due to the variable oxidation states being studied. The $z$ axis (not shown) is perpendicular to the plane of the page.

that were used to describe magnetic properties as well as a mechanism for electron transfer in these compounds. Density functional theory (DFT) has been applied to the free semiquinone ligand, ${ }^{31}$ but a comprehensive study of the entire redox series has not been reported.

In an effort to improve our understanding of the electronic structure of o-quinones and, by extension, metal complexes containing these ligands, we have applied self-consistent field density functional theory to elucidate the electronic structure of 3,6-di-tert-butylorthoquinone, 3,6-di-tert-butylorthosemiquinone, and 3,6-di-tert-butylorthocatechol. In this work, the optimized geometries of the three forms of the 3,6-di-tert-butyl substituted quinone will be discussed, as well as the effect of changes in oxidation state on the relative molecular orbital energies and charge distributions among the three accessible oxidation states of the molecule. Finally, we will examine substituent effects on the overall energetics of the molecule through a comparison of the electronic structures of the 3,5di-tert-butylorthosemiquinone and 3,6-di-tert-butylorthosemiquinone isomers.

\section{Experimental Section}

General Methods. All self-consistent field density functional calculations were performed using the Gaussian $94^{36}$ and Gaussian $98^{37}$ suites of programs. Two different functionals were used for the calculations. The B-LYP functional combines the gradient-corrected Becke (B) exchange with the nonlocal correlation functional of Lee, Yang, and Parr (LYP). ${ }^{38}$ The hybrid B3-LYP functional combines the three parameter exchange of Becke $\mathrm{e}^{39-41}$ with the LYP correlation functional. All calculations were performed using tight convergence criteria. ${ }^{42}$ Analyses of atomic charge were performed within the natural population analyses (NPA) framework developed by Weinhold et $\mathrm{al}^{47-49}$

Geometry Optimizations. The initial geometries of the molecules were generated with SPARTAN ${ }^{43}$ and optimized in three steps. First, the geometry was optimized using either restricted Hartree-Fock (RHF) methods for closed-shell molecules or restricted open shell Hartree-Fock (ROHF) for openshell molecules and a STO-3G** basis set. No geometrical constraints were imposed on the molecule (i.e., $C_{1}$ symmetry was assumed). The labeling scheme used for all molecules is shown in Figure 1. Following this initial phase, a second optimization was performed at the BLYP/3-21G** level employing either restricted density functional theory (RDFT) or restricted open-shell density functional theory (RODFT) for
TABLE 1: Selected Bond Lengths (̊̊) and Angles (deg) for 1,2-benzoquinone Obtained from Single-Crystal X-ray Diffraction (Exp) and a SCF Geometry Optimization at the BLYP/6-31G* and B3LYP/6-31G* Levels

\begin{tabular}{lrrr}
\hline & $\exp ^{a}$ & BLYP/6-31G* & B3LYP/6-31G* \\
\hline & & Bond Lengths \\
$\mathrm{C}(1)-\mathrm{O}(1)$ & 1.216 & 1.233 & 1.218 \\
$\mathrm{C}(2)-\mathrm{O}(2)$ & 1.216 & 1.233 & 1.218 \\
$\mathrm{C}(1)-\mathrm{C}(2)$ & 1.541 & 1.580 & 1.561 \\
$\mathrm{C}(2)-\mathrm{C}(3)$ & 1.463 & 1.480 & 1.475 \\
$\mathrm{C}(3)-\mathrm{C}(4)$ & 1.366 & 1.364 & 1.350 \\
$\mathrm{C}(4)-\mathrm{C}(5)$ & 1.445 & 1.467 & 1.463 \\
$\mathrm{C}(5)-\mathrm{C}(6)$ & 1.336 & 1.364 & 1.350 \\
$\mathrm{C}(1)-\mathrm{C}(6)$ & 1.463 & 1.481 & 1.475 \\
& & Bond Angles & \\
O1-C1-C2 & 123.0 & 120.0 & 119.9 \\
C2-C1-C6 & 117.3 & 117.0 & 117.2 \\
C1-C6-C5 & 119.9 & 120.6 & 120.5 \\
C6-C5-C4 & 122.6 & 122.3 & 122.3
\end{tabular}
473.

${ }^{a}$ Macdonald, A. L.; Trotter, J. J. Chem. Soc., Perkin Trans. 2 1973,

closed-shell and open-shell molecules, respectively. The final optimization was performed at both BLYP/6-31G* and B3LYP/ 6-31G* levels using either RDFT or RODFT. The optimized geometries obtained from the B3LYP/6-31G* level were used in further single point calculations.

Separate geometry optimizations were done for both 3,6DTBQ and 3,6-DTBCat assuming singlet and triplet configurations. In both cases, the optimized structures for the singlet produced lower total SCF energies relative to the triplet, confirming that the singlet is the ground state in each case. Similar calculations were carried out for the doublet and quartet states of 3,6-DTBSQ and 3,5-DTBSQ. The total optimized SCF energies of both semiquinone isomers were lower for the doublet configuration, thus confirming doublet ground states for these compounds.

Single Point Calculations. Calculations for 3,6-di-tertbutylorthoquinone (3,6-DTBQ), employing a 6-311G** basis set and the B3LYP functional, were performed assuming a singlet ground state and a molecular charge of zero. Calculations for both 3,6-di-tert-butylorthosemiquinone (3,6-DTBSQ) and 3,5-di-tert-butylorthosemiquinone (3,5-DTBSQ) employed a $6-311 \mathrm{G}^{* *}$ basis set and the B3LYP functional assuming a doublet ground state and a molecular charge of -1 . Calculations for 3,6-di-tert-butylorthocatechol (3,6-DTBCat) employed the 6-311G** basis set and the B3LYP functional assuming a singlet ground state and a molecular charge of -2 .

\section{Results and Discussion}

Geometry Optimization of 1,2-Benzoquinone. To our knowledge there have not been crystal structures reported for the three oxidation states of the 3,6-di-tert-butylorthoquinone molecule which are studied in this work. However, an X-ray structure has been reported for the closely related molecule 1,2benzoquinone with parameters given in Table $1 .{ }^{44}$

To compare structural parameters obtained from theory and experiment we have performed a geometry optimization for 1,2benzoquinone. This allows us to estimate the differences expected between X-ray and optimized structures for the molecules of present interest. Some knowledge of the differences between X-ray and optimized structures is highly desirable when experimental structures are not available, and therefore, one has to rely completely on calculated parameters.

The results are presented in Table 1. It shows that the X-ray structure displays a combination of single and double bonds 
TABLE 2: Selected Optimized Bond Lengths (̊̊) and Bonding Angles (deg) for 3,6-DTBQ, 3,6-DTBSQ, 3,5-DTBSQ, and 3,6-DTBCat Obtained from SCF Geometry Optimizations at the BLYP/6-31G* and B3LYP/6-31G* Levels

\begin{tabular}{|c|c|c|c|c|c|c|c|c|}
\hline & \multicolumn{2}{|c|}{ 3,6-DTBQ } & \multicolumn{2}{|c|}{ 3,6-DTBSQ } & \multicolumn{2}{|c|}{ 3,5-DTBSQ } & \multicolumn{2}{|c|}{ 3,6-DTBCat } \\
\hline & BLYP & B3LYP & BLYP & B3LYP & BLYP & B3LYP & BLYP & B3LYP \\
\hline \multicolumn{9}{|c|}{ Bond Lengths } \\
\hline $\mathrm{C} 1-\mathrm{O} 1$ & 1.235 & 1.220 & 1.274 & 1.261 & 1.269 & 1.256 & 1.307 & 1.293 \\
\hline $\mathrm{C} 2-\mathrm{O} 2$ & 1.235 & 1.220 & 1.274 & 1.261 & 1.275 & 1.261 & 1.307 & 1.293 \\
\hline $\mathrm{C} 1-\mathrm{C} 2$ & 1.596 & 1.575 & 1.532 & 1.514 & 1.525 & 1.507 & 1.518 & 1.504 \\
\hline $\mathrm{C} 2-\mathrm{C} 3$ & 1.492 & 1.485 & 1.470 & 1.460 & 1.473 & 1.462 & 1.451 & 1.437 \\
\hline $\mathrm{C} 3-\mathrm{C} 4$ & 1.371 & 1.356 & 1.396 & 1.383 & 1.398 & 1.386 & 1.431 & 1.422 \\
\hline $\mathrm{C} 4-\mathrm{C} 5$ & 1.463 & 1.460 & 1.428 & 1.420 & 1.439 & 1.430 & 1.399 & 1.386 \\
\hline $\mathrm{C} 5-\mathrm{C} 6$ & 1.371 & 1.356 & 1.396 & 1.383 & 1.393 & 1.380 & 1.431 & 1.422 \\
\hline $\mathrm{C} 1-\mathrm{C} 6$ & 1.492 & 1.485 & 1.470 & 1.460 & 1.454 & 1.445 & 1.451 & 1.437 \\
\hline \multicolumn{9}{|c|}{ Bond Angles } \\
\hline $\mathrm{O} 1-\mathrm{C} 1-\mathrm{C} 2$ & 116.6 & 116.6 & 118.3 & 118.4 & 120.8 & 120.9 & 118.8 & 119.0 \\
\hline $\mathrm{O} 2-\mathrm{C} 2-\mathrm{C} 1$ & 116.6 & 116.6 & 118.3 & 118.4 & 119.2 & 119.4 & 118.8 & 119.0 \\
\hline $\mathrm{C} 2-\mathrm{C} 1-\mathrm{C} 6$ & 119.2 & 119.2 & 118.7 & 118.8 & 117.6 & 117.7 & 118.1 & 118.1 \\
\hline $\mathrm{C} 1-\mathrm{C} 6-\mathrm{C} 5$ & 115.5 & 115.5 & 118.3 & 118.4 & 123.2 & 123.2 & 120.6 & 120.7 \\
\hline $\mathrm{C} 6-\mathrm{C} 5-\mathrm{C} 4$ & 125.4 & 125.3 & 122.9 & 122.8 & 118.2 & 118.2 & 121.3 & 121.2 \\
\hline
\end{tabular}

which are well reproduced by the calculations. Thus, 1,2benzoquinone can be represented by the following picture:

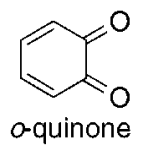

For all the bond lengths listed, the B3LYP values are shorter and in closer agreement with the X-ray structure than those corresponding to BLYP. The largest difference between calculated and experimental parameters is found for $\mathrm{C} 1-\mathrm{C} 2$ with B3LYP and BLYP distances 0.020 and $0.039 \AA$ longer, respectively, than the $\mathrm{X}$-ray structure. The values for $\mathrm{C} 1-\mathrm{O} 1$ and $\mathrm{C} 2-\mathrm{O} 2$ predicted by B3LYP are essentially equal to those of the X-ray structure if one considers the reported experimental uncertainty, ${ }^{44}$ but the corresponding BLYP distances are 0.017 Å longer.

The bonding angles predicted by both methods are in close agreement. Thus, while the largest difference between bond lengths predicted by BLYP and B3LYP is $0.019 \AA$ (about $1.2 \%$ ) for $\mathrm{C} 1-\mathrm{C} 2$, the largest difference between their bonding angles is $0.2^{\circ}$ (about $0.2 \%$ ) for $\mathrm{C} 2-\mathrm{C} 1-\mathrm{C} 6$.

Since no X-ray structures are available for 3,6-DTBQ, 3,6DTBSQ, 3,5-DTBSQ, or 3,6-DTBCat, we can estimate possible discrepancies between their optimized parameters and experiment from the previous comparison made for 1,2-benzoquinone. For the molecules of present interest we expect that experimental and theoretical (U-B3LYP/6-31G*) C-O bond lengths will be essentially equal whereas theoretical $\mathrm{C}-\mathrm{C}$ bonds within the sixmembered ring will be slightly longer (i.e., $0.01-0.02 \AA$ ).

Geometric Structure across the 3,6-DTBQ Redox Series. The structural parameters obtained from the optimization of 3,6DTBQ, 3,6-DTBSQ, and 3,6-DTBCat are presented in Table 2. Although results from both BLYP and B3LYP optimizations are given in Table 2, we shall focus mainly on parameters obtained from the B3LYP calculation. A comparison of Tables 1 and 2 shows the trends from the X-ray structure of $o$-quinone are also observed in the optimized geometry of 3,6-DTBQ. The longest bond is $1.575 \AA$ between $\mathrm{C} 1-\mathrm{C} 2$ followed by $\mathrm{C} 2-\mathrm{C} 3$ and $\mathrm{C} 1-\mathrm{C} 6$ at $1.485 \AA$, with $\mathrm{C} 4-\mathrm{C} 5$ exhibiting a slightly shorter bond of $1.460 \AA$ A. Finally, the $\mathrm{C}-\mathrm{C}$ bonds which reflect the most double bond character in the quinone crystal structure are also the shortest bonds in the optimized structure: $\mathrm{C} 3-\mathrm{C} 4$ and $\mathrm{C} 5-\mathrm{C} 6$ both exhibit distances of $1.356 \AA$. The bonds between $\mathrm{C} 1-\mathrm{O} 1$ and $\mathrm{C} 2-\mathrm{O} 2$ also exhibit double bond character with distances of $1.220 \AA$.
Upon one electron reduction of the quinone, the molecule is expected to undergo some geometric changes. We find that the $\mathrm{C} 1-\mathrm{O} 1$ and $\mathrm{C} 2-\mathrm{O} 2$ bonds both increase $0.041 \AA$ to $1.261 \AA$ in 3,6-DTBSQ. This increase in the carbon-oxygen bond lengths is reasonable given that one-electron reduction formally eliminates one $\mathrm{C}-\mathrm{O}$ double bond to yield a double bond best described as delocalized over two carbon-oxygen pairs. Bond distances within the carbon ring are also affected by the addition of an electron. Specifically, the bonds between $\mathrm{C} 1-\mathrm{C} 6$ and $\mathrm{C} 2-$ C3 shorten by ca. $0.025 \AA$ to $1.460 \AA$ in the semiquinone, whereas the $\mathrm{C} 5-\mathrm{C} 6$ and $\mathrm{C} 3-\mathrm{C} 4$ bonds elongate from a distance of $1.356 \AA$ in the quinone to $1.383 \AA$ in the semiquinone. Again, these changes are quite reasonable in terms of the bonding and antibonding interactions present in the LUMO of 3,6-DTBQ which becomes occupied upon reduction to 3,6-DTBSQ (vida infra).

Addition of a second electron produces the catechol with an overall charge of -2 and a singlet ground state. This reduction causes $\mathrm{C} 1-\mathrm{O} 1$ and $\mathrm{C} 2-\mathrm{O} 2$ bond lengths to increase from 1.261 $\AA$ to $1.293 \AA$ in the catechol. This corresponds to an overall increase of $0.073 \AA$ as compared to the quinone form: these bonds are now clearly single bonds. The longest bond in the molecule is still between $\mathrm{C} 1$ and $\mathrm{C} 2$ at $1.504 \AA$, but the remaining $\mathrm{C}-\mathrm{C}$ bonds now cover a much narrower range (cf. $1.41 \pm 0.03 \AA$ ) as compared to the two previous oxidation states. This is consistent with the aromatic nature of the carbon ring. As was suggested in the case of the 1,2-benzoquinone structure, the unusually long bond between $\mathrm{C} 1$ and $\mathrm{C} 2$ is most likely attributable to the electron-withdrawing capability of the neighboring oxygen atoms which weakens the $\mathrm{C} 1-\mathrm{C} 2$ bond by introducing $\delta+$ charges on these carbons.

In summary, some clear trends can be extracted from the optimized structures of 3,6-DTBQ, 3,6-DTBSQ, and 3,6DTBCat (Table 2). As the molecule is systematically reduced, we observe that the $\mathrm{C}-\mathrm{O}$ bond lengths increase by about $0.03-$ $0.04 \AA$ for each reductive equivalent; a similar trend is noted for $\mathrm{C} 3-\mathrm{C} 4$ and $\mathrm{C} 5-\mathrm{C} 6$. The $\mathrm{C} 2-\mathrm{C} 3, \mathrm{C} 4-\mathrm{C} 5$, and $\mathrm{C} 1-\mathrm{C} 6$ bond lengths, on the other hand, all decrease by about $0.02-$ $0.03 \AA$ for each additional electron. Finally, the longest carboncarbon bond, corresponding to $\mathrm{C} 1-\mathrm{C} 2$, shortens considerably (by about $0.06 \AA$ ) upon reduction from quinone to semiquinone, but is only slightly perturbed upon further reduction to the catechol. The general tendency toward equivalence of metric details within the ring upon reduction is further reflected in the bond angles. For example, for 3,6-DTBQ the difference between 
TABLE 3: Total Self-Consistent Field Energies Obtained Using the 6-311G** Basis and the Optimized Geometries of Each Ligand

\begin{tabular}{lccc}
\hline \multicolumn{1}{c}{ molecule } & $2 S+1$ & $E_{\text {UB3LYP }}($ hartree $)$ & $E_{\text {UBLYP }}$ (hartree) \\
\hline 3,6-DTBQ & 0 & -696.139079 & -695.820700 \\
3,6-DTBSQ & 2 & -696.209575 & -695.885549 \\
3,5-DTBSQ & 2 & -696.206116 & -695.881893 \\
3,6-DTBCat & 0 & -696.097124 & -695.770274
\end{tabular}

the $\mathrm{C} 1-\mathrm{C} 6-\mathrm{C} 5$ and $\mathrm{C} 6-\mathrm{C} 5-\mathrm{C} 4$ angles is $9.8^{\circ}$ whereas for 3,6 -DTBCat this difference is only $0.5^{\circ}$.

\section{Electronic Structure of Quinoids}

One of the primary goals of this work was to understand the variations in electronic structure of the quinoidal ligand as a function of oxidation state. We were not only interested in how the spatial distribution of the molecular orbitals changed upon reduction but also how the relative ordering of energy levels was being modified across the redox series. To determine the composition and energy of the one-electron orbitals, we performed SCF density functional calculations for the three oxidation states at the U-B3LYP/6-311G** level using the optimized structures described above. The results we obtained are in qualitative agreement with those previously reported by Adams et al. ${ }^{32}$ from calculations performed on unsubstituted quinone as well as those we recently obtained for the semiquinone itself in the context of our previous study on $[\mathrm{Cr}(\operatorname{tren})$ (3,6-DTBSQ) ${ }^{+2} .{ }^{31}$ Table 3 lists the total self-consistent field energies for all three molecules in the 3,6-DTBQ series, as well as the 3,5 isomer to be discussed later. Calculations were performed using both the UBLYP and UB3LYP functionals. However, as was done above, our discussions will primarily focus on results obtained from the hybrid method.

3,6-Di-tert-butylorthoquinone. Since the semiquinone radical has an open-shell structure, we chose to perform spin unrestricted calculations on all of the molecules so that direct comparisons could be made across the redox series. Table 4 lists the energies and composition of orbitals 58-62 for 3,6DTBQ. These are the highest occupied and lowest unoccupied molecular orbitals and are referenced to the coordinate system shown in Figure 1. For 3,6-DTBQ, a closed-shell molecule, the $\alpha$ and $\beta$ orbitals of each pair were found to be of identical composition and energy, as expected.

Occupied molecular orbitals $58 \alpha, \beta$ are mostly composed of a combination of oxygen $\mathrm{p}_{x}$ and $\mathrm{p}_{y}$ orbitals with small contributions from the ring carbons. Each oxygen orbital contributes $21.94 \%$ to this $\mathrm{MO}$, while $\mathrm{C} 1$ and $\mathrm{C} 2$ each contribute $10.06 \%$; the remaining carbon atoms each contribute less than $5 \%$. Figure 2 shows that the two oxygen orbitals are relatively isolated from each other, allowing for only weak $\sigma$-antibonding interactions between the orbitals.

MOs $59 \alpha, \beta$ have small contributions from the $\mathrm{p}_{z}$ orbitals on both oxygens as shown in Figure 3. However, the main contributions to this $\mathrm{MO}$ are from the $\mathrm{p}_{z}$ orbitals of the ring
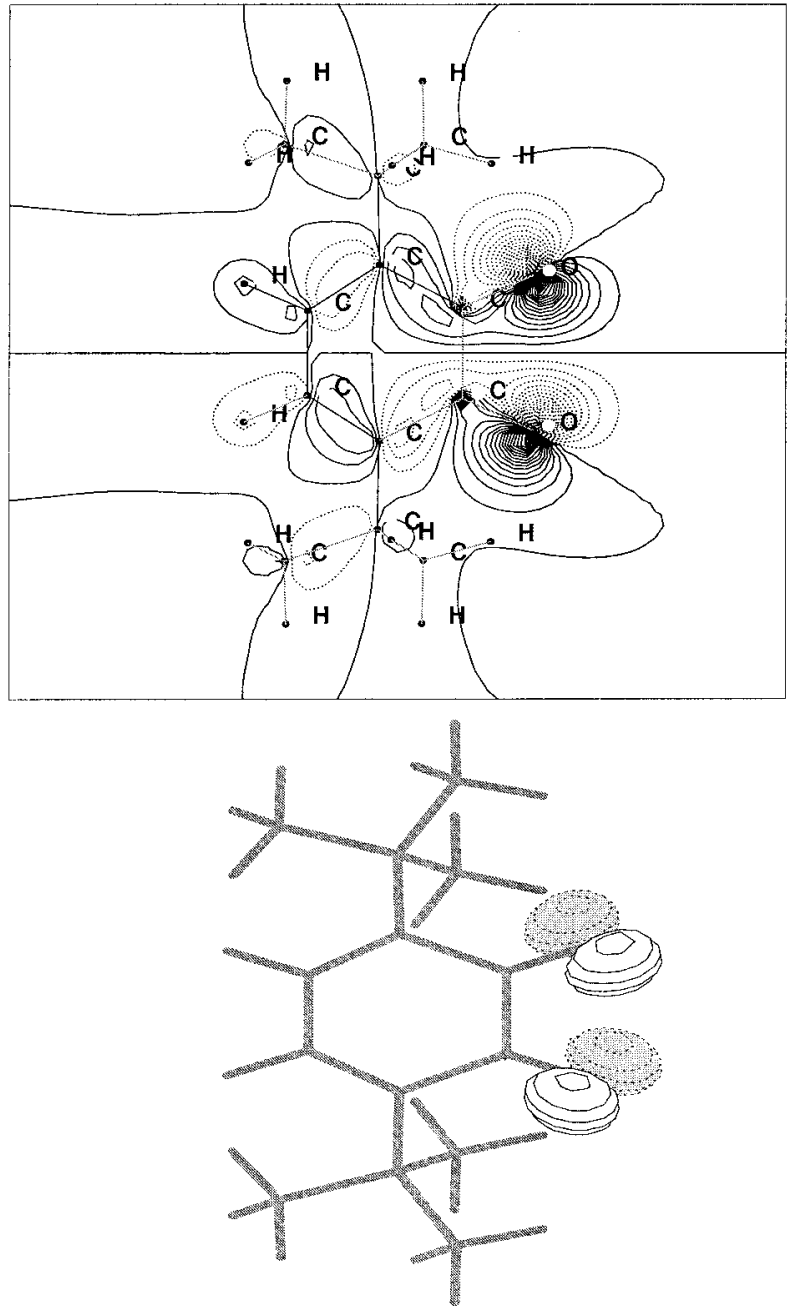

Figure 2. MO $58 \alpha$ of 3,6-di-tert-butylquinone. Top: Isovalue contour plot displaying the electron density obtained at the U-B3LYP/6-311G** level. The contour shows a weak $\sigma$-antibonding interaction between the oxygen orbitals. Bottom: MO $58 \alpha$ of 3,6-DTBQ. The orbital lies in the $x y$ plane.

carbons. C3 and C6 contribute the most at $15.80 \%$ each, with somewhat smaller contributions from $\mathrm{C} 4$ and $\mathrm{C} 5$ of $8.86 \%$ each. Figure 3 illustrates the $\pi$-bonding interaction that exists between $\mathrm{C} 3$ and $\mathrm{C} 4$ and also between $\mathrm{C} 5$ and C6. The weak $\pi$-antibonding interaction between $\mathrm{C} 4$ and $\mathrm{C} 5$ combined with that of $\mathrm{O} 1$ and $\mathrm{O} 2$ helps to define a nodal plane coincident with the pseudo- $C_{2}$ axis of the molecule.

MOs $60 \alpha, \beta$ are the HOMOs for 3,6-DTBQ. Although the relative phases of the oxygen orbitals suggest a bonding interaction, the two are essentially isolated from each other. These orbitals have main contributions of nearly $18.5 \%$ from the $\mathrm{p}_{x}$ and $\mathrm{p}_{y}$ orbitals of $\mathrm{O} 2$ and $\mathrm{O} 1$, respectively. As shown in Table 4, C3 and C6 each contribute $12.44 \%$ while C1 and C2 both contribute $8.79 \%$; C4 and C5 both contribute less than

TABLE 4: Energies and Percent Atomic Contributions to the Frontier Molecular Orbitals of 3,6-DTBQ Obtained at the U-B3LYP/6-311G** Level

\begin{tabular}{rccrrrrrrrr}
\hline orbital $^{a}$ & type $^{b}$ & energy (eV) & \% O1 & \% O2 & \% C1 & \% C2 & \% C3 & \% C4 & \% C5 & \% C6 \\
\hline $62 \alpha, \beta$ & $\mathrm{V}$ & -0.221 & 4.39 & 4.39 & 10.25 & 10.25 & 20.09 & 5.19 & 5.19 & 20.09 \\
$61 \alpha, \beta$ & $\mathrm{V}$ & -3.535 & 14.39 & 14.39 & 7.92 & 7.92 & 8.01 & 8.32 & 8.32 & 8.01 \\
$60 \alpha, \beta$ & $\mathrm{O}$ & -6.765 & 18.46 & 18.46 & 8.79 & 8.79 & 12.44 & 0.58 & 0.58 & 12.44 \\
$59 \alpha, \beta$ & $\mathrm{O}$ & -6.901 & 4.19 & 4.19 & 0.20 & 0.20 & 15.80 & 8.86 & 8.86 & 15.80 \\
$58 \alpha, \beta$ & $\mathrm{O}$ & -8.003 & 21.94 & 21.94 & 10.06 & 10.06 & 4.36 & 0.94 & 0.94 & 4.36
\end{tabular}

${ }^{a}$ The $\alpha$ and $\beta$ orbitals for this closed-shell molecule were found to have identical compositions and are therefore listed jointly. ${ }^{b} \mathrm{~V}=$ virtual (unoccupied); $\mathrm{O}=$ occupied. 

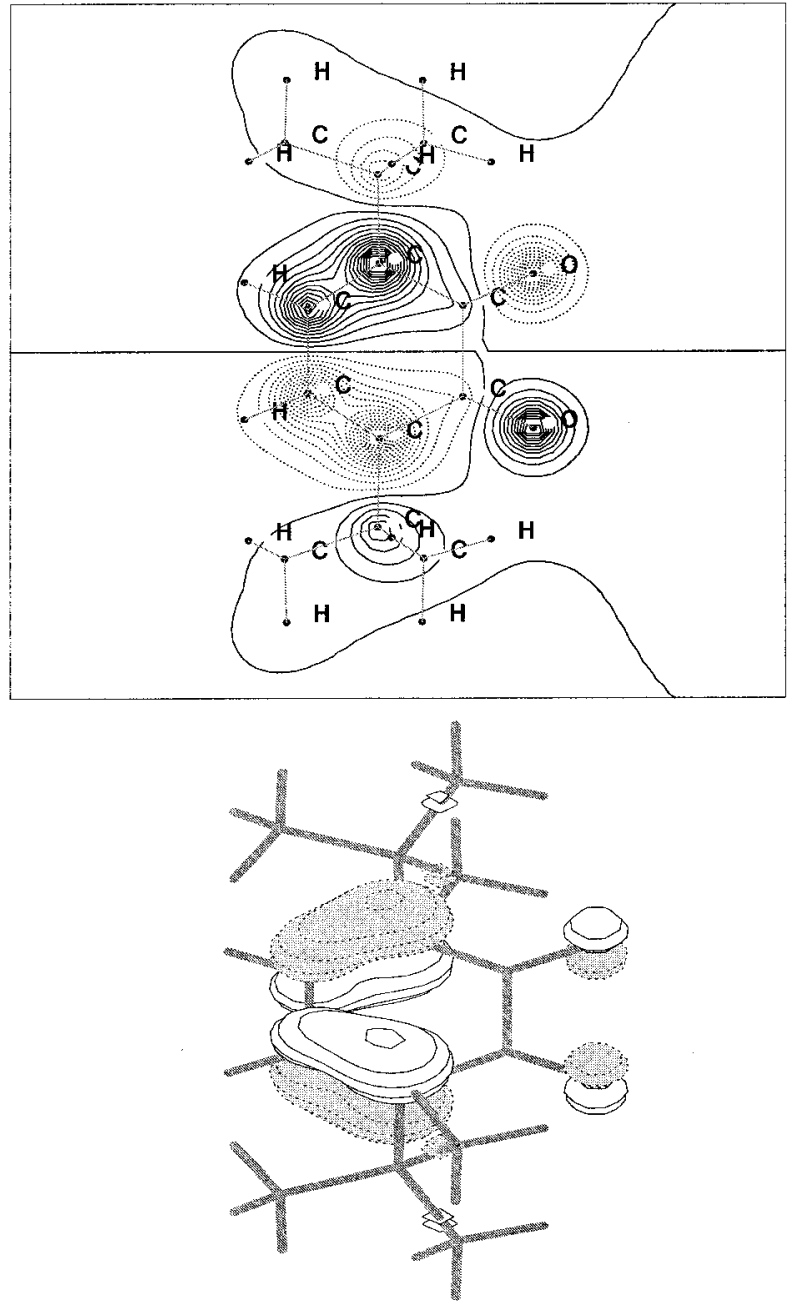

Figure 3. MO $59 \alpha$ of 3,6-di-tert-butylquinone. Top: Isovalue contour plot displaying the electron density obtained at the U-B3LYP/6-311G** level. The contour is a slice taken $0.5 \AA$ above the $x y$ plane and shows the $\pi$-interactions between the $\mathrm{C}\left(\mathrm{p}_{z}\right)$ orbitals of the ring. Bottom: MO $59 \alpha$ of 3,6-DTBQ. The orbital density is localized above and below the plane of the ring.

$1 \%$. Figure 4 shows the principal $\pi$-antibonding interaction between oxygen and carbon orbitals. In addition, there are $\sigma$-bonding interaction between $\mathrm{C} 1$ and $\mathrm{C} 2$ and very weak bonding interactions in the $\mathrm{C} 1-\mathrm{C} 6$ and $\mathrm{C} 2-\mathrm{C} 3$ pairs.

The quinone LUMOs ( $61 \alpha$ and $-\beta$, Figure 5$)$ are comprised mainly of $\mathrm{p}_{z}$ oribitals on the oxygen atoms, each contributing nearly $14.4 \%$. Table 4 shows that $\mathrm{p}_{z}$ orbitals of the ring carbon atoms all contribute approximately $8 \%$. The contour in Figure 5 shows the main $\pi$-antibonding interaction between oxygen and carbon atoms and, in addition, the $\pi$-bonding interactions among $\mathrm{C} 6, \mathrm{C} 1, \mathrm{C} 2$, and $\mathrm{C} 3$ and also between $\mathrm{C} 4$ and $\mathrm{C} 5$. There are also antibonding interactions between $\mathrm{C} 3-\mathrm{C} 4$ and $\mathrm{C5}-\mathrm{C} 6$. Finally, we note that the antibonding $\mathrm{C}-\mathrm{O}$ interactions in this quinone LUMO will become more significant when reduction to the semiquinone is considered below.

The last orbitals we will consider are MOs $62 \alpha, \beta$. Main contributions to these MOs come from $\mathrm{p}_{z}$ orbitals on $\mathrm{C} 3$ and C6 (20.09\% each) as well as C4 and C5 (5.19\% each). In addition, there are smaller contributions from $\mathrm{O} 1$ and $\mathrm{O} 2$ of $4.39 \%$ each. The contour plot for $62 \alpha$ is shown in Figure 6. It clearly shows the $\pi$-antibonding interaction between the oxygens and carbon atoms, as well as the $\pi$-antibonding interactions that exist all around the ring. The strongly antibonding nature of this MO no doubt contributes to the more than $3.31 \mathrm{eV}$ energy
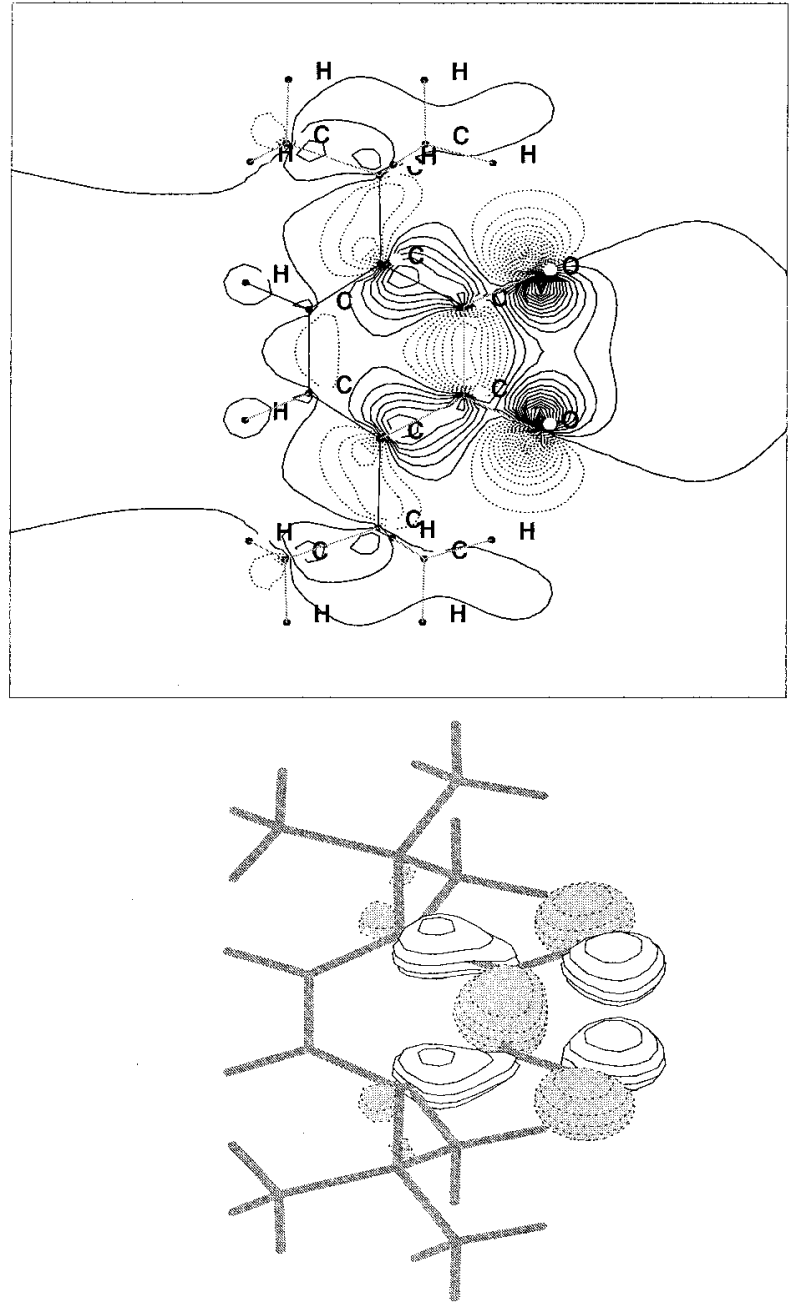

Figure 4. MO $60 \alpha$ of 3,6-di-tert-butylquinone (HOMO). Top: Isovalue contour plot displaying the electron density obtained at the U-B3LYP/ $6-311 \mathrm{G}^{* *}$ level. The contour shows a weak $\sigma$-bonding interaction between the oxygen orbitals. Bottom: MO $60 \alpha$ of 3,6-DTBQ. The orbital lies in the $x y$ plane.

difference between this MO and MO $61 \alpha$, as compared to the ca. $3.23 \mathrm{eV}$ HOMO-LUMO gap between $60 \alpha$ and $61 \alpha$ (vida infra).

3,6-Di-tert-butylorthosemiquinone. The next step in our analysis was to determine how the addition of one electron perturbs the electronic structure of the quinone. Recently we described in detail an analysis of the electronic structure of 3,6DTBSQ in the context of our work on $[\mathrm{Cr}(\operatorname{tren})(3,6-\mathrm{DT}-$ BSQ) $]^{2+} .31$ Although calculations employing both the BLYP and B3LYP functionals were carried out, this previous study focused primarily on the BLYP results for 3,6-DTBSQ. To allow for a more direct comparison of all members of the redox series in our present study, we herein describe the results of calculations using the B3LYP functionals and a $6-311 \mathrm{G}^{* *}$ basis set. Table 5 lists the energies and composition of the orbitals 5862. Rather than detailing the entire electronic configuration, we shall for the purpose of discussion only highlight some of the similarities and differences we observe between the electronic structure of 3,6-DTBSQ and that of 3,6-DTBQ.

Clearly, the reduction of 3,6-DTBQ to 3,6-DTBSQ causes some important in the molecular properties, e.g., the diamagnetism of 3,6-DTBQ versus the paramagnetism of 3,6-DTBSQ. However, with the obvious exception that 3,6-DTBSQ has one more electron than 3,6-DTBQ, we find that the overall molecular orbital compositions of the two molecules are remarkably 

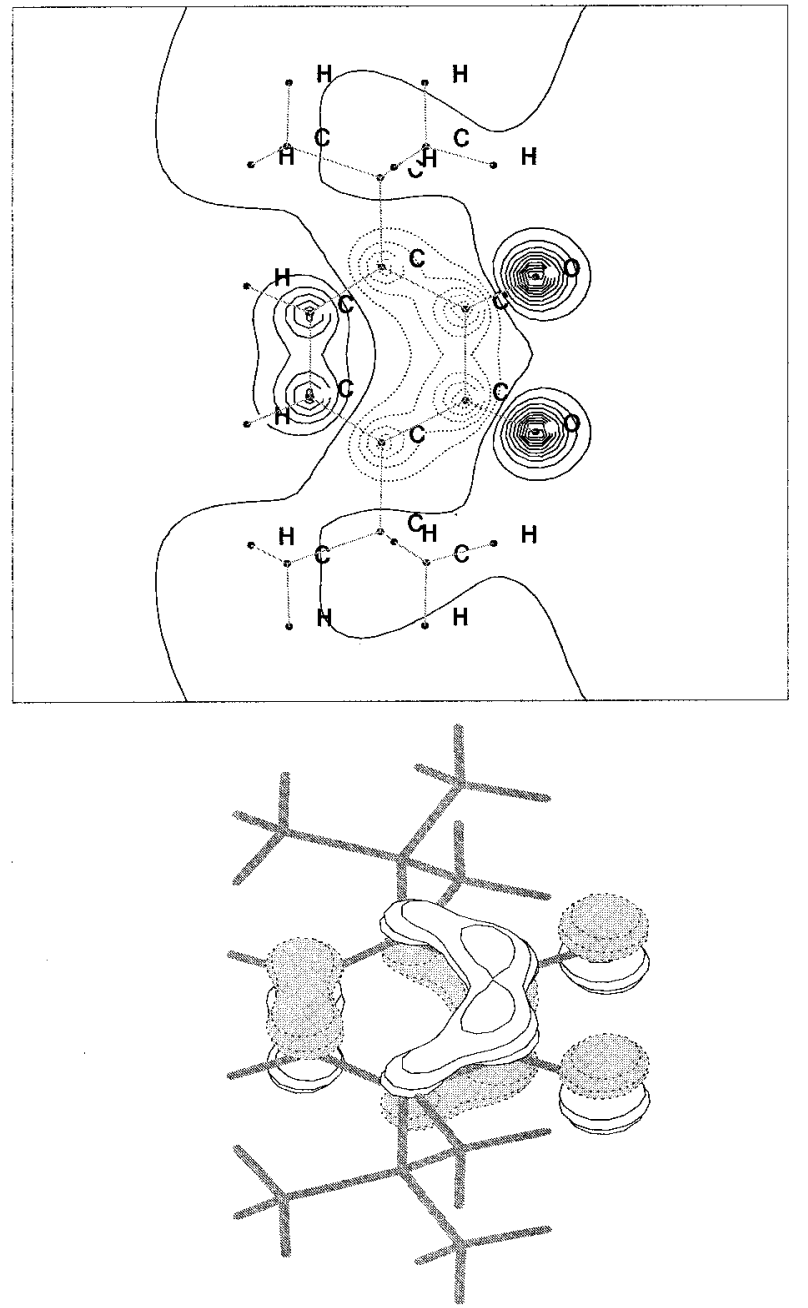

Figure 5. MO 61 $\alpha$ of 3,6-di-tert-butylquinone (LUMO). Top: Isovalue contour plot displaying the electron density obtained at the U-B3LYP/ 6-311G** level. The contour is a slice taken $0.5 \AA$ above the $x y$ plane and shows the $\pi$-antibonding interactions between the $\mathrm{C}\left(\mathrm{p}_{z}\right)$ and $\mathrm{O}\left(\mathrm{p}_{z}\right)$ orbitals. Bottom: MO $61 \alpha$ of 3,6-DTBQ. The orbital density is localized above and below the plane of the ring.

similar. For example, a comparison of Tables 4 and 5 reveals that the spatial distributions of MO $58 \alpha$ are virtually identical save for a slight increase in contributions from $\mathrm{O} 1$ and $\mathrm{O} 2$ of ca. $3 \%$ in the case of 3,6-DTBSQ. This is most likely a manifestation of the greater electronegativity of oxygen versus carbon and an effort to stabilize the higher negative charge density of the semiquinone (vida infra). In fact, this appears to be a general trend for the remaining occupied frontier orbitals: the oxygen atoms of 3,6-DTBSQ contribute more to each MO (ca. >3\%) whereas the carbon atoms of the ring show only a minimal change in their contribution relative to that seen for 3,6-DTBQ.

Except for these (relatively) minor differences in atomic orbital contributions, we see remarkable homology in orbital compositions between the two oxidation states. Particularly striking along these lines is MO $61 \alpha$. Despite the fact that this MO is unoccupied in 3,6-DTBQ and occupied in 3,6-DTBSQ, its spatial distribution remains virtually unchanged. Thus, on a qualitative or even semiquantitative level, the Aufbau principal essentially works in this system: the electronic structure of 3,6DTBSQ can be quite reasonably thought of in terms of placing an electron in the LUMO of 3,6-DTBQ. While both the absolute and relative energies of the orbitals change (vida infra), the basic descriptions and ordering of the MOs remains intact.

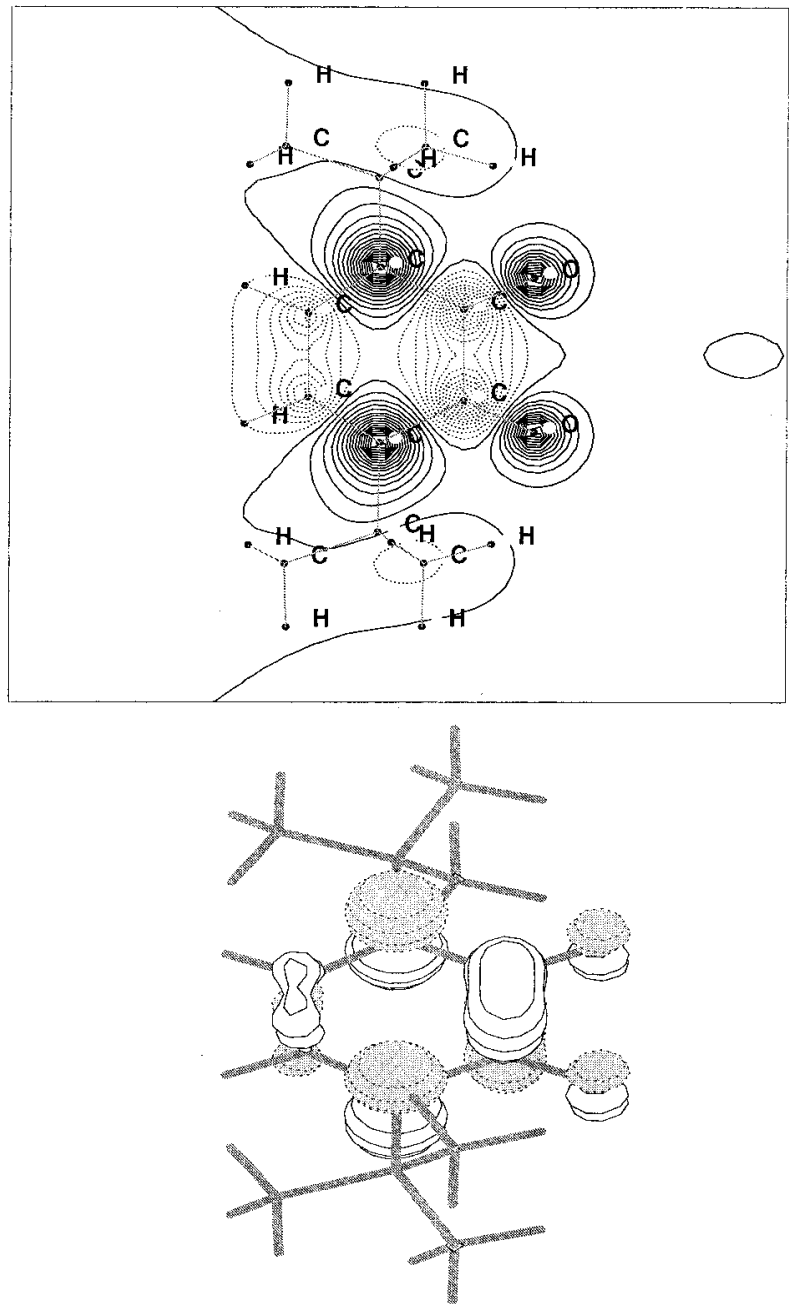

Figure 6. MO $62 \alpha$ of 3,6-di-tert-butylquinone. Top: Isovalue contour plot displaying the electron density obtained at the U-B3LYP/6-311G** level. The contour is a slice taken $0.5 \AA$ above the $x y$ plane and shows the multiple $\pi$-antibonding interactions throughout the molecule. Bottom: MO $62 \alpha$ of 3,6-DTBQ. The orbital density is localized above and below the plane of the ring.

With these results in hand, an examination of the now occupied MO $61 \alpha$ (Figure 7) provides a straightforward explanation for the bond distance changes noted upon reduction of 3,6-DTBQ to 3,6-DTBSQ. As stated previously (Table 2), the $\mathrm{C} 1-\mathrm{O} 1, \mathrm{C} 2-\mathrm{O} 2, \mathrm{C} 3-\mathrm{C} 4$, and $\mathrm{C} 5-\mathrm{C} 6$ bonds all lengthen upon reduction, whereas $\mathrm{C} 1-\mathrm{C} 2, \mathrm{C} 2-\mathrm{C} 3, \mathrm{C} 4-\mathrm{C} 5$, and $\mathrm{C} 1-$ C6 all decrease. These changes correspond exactly to what we would expect upon population of $61 \alpha$ of 3,6 -DTBQ. That is, addition of an electron to 3,6-DTBQ should cause a decrease in bond distances for those atoms involved in bonding interactions and an increase in bond distance for those atoms involved in antibonding interactions. At the same time, it is significant that the composition of MO $61 \beta$ displays some subtle, but nevertheless significant, changes within the six-membered ring relative to MO 61a. In fact, Table 5 reveals that MO $61 \alpha$ of 3,6 -DTBSQ resembles very closely MOs $61 \alpha, \beta$ of 3,6-DTBQ. However, MO $61 \beta$ of 3,6-DTBSQ resembles very closely MOs $61 \alpha, \beta$ of 3,6-DTBCat. Clearly, the exchange interactions between the majority $\alpha$ electrons of 3,6-DTBSQ do reflect not only in the energy difference between MOs $61 \alpha$ and $61 \beta$ but also in their spatial distributions.

3,6-Di-tert-butylorthocatechol. Further reduction of the semiquinone by one electron yields the corresponding catechol with a charge of -2 . Table 6 lists the energies and composition 
TABLE 5: Energies and Percent Atomic Contributions to the Frontier Molecular Orbitals of 3,6-DTBSQ Obtained at the U-B3LYP/6-311G** Level

\begin{tabular}{|c|c|c|c|c|c|c|c|c|c|c|}
\hline orbital & type $^{a}$ & energy $(\mathrm{eV})$ & $\% \mathrm{O} 1$ & $\% \mathrm{O} 2$ & $\% \mathrm{C} 1$ & $\% \mathrm{C} 2$ & $\% \mathrm{C} 3$ & $\% \mathrm{C} 4$ & $\% \mathrm{C} 5$ & $\% \mathrm{C} 6$ \\
\hline $62 \alpha$ & $\mathrm{V}$ & +4.097 & 2.86 & 2.86 & 8.16 & 8.16 & 13.84 & 3.39 & 3.39 & 13.84 \\
\hline $61 \alpha$ & $\mathrm{O}$ & -0.416 & 14.32 & 14.32 & 6.78 & 6.78 & 8.32 & 8.12 & 8.12 & 8.32 \\
\hline $60 \alpha$ & $\mathrm{O}$ & -1.792 & 20.03 & 20.03 & 8.16 & 8.16 & 12.82 & 0.43 & 0.43 & 12.82 \\
\hline $59 \alpha$ & $\mathrm{O}$ & -2.236 & 5.42 & 5.42 & 0.28 & 0.28 & 16.00 & 7.61 & 7.61 & 16.00 \\
\hline $58 \alpha$ & $\mathrm{O}$ & -2.610 & 24.21 & 24.21 & 10.20 & 10.20 & 5.61 & 0.49 & 0.49 & 5.61 \\
\hline $62 \beta$ & V & +4.101 & 0.11 & 0.11 & 0.18 & 0.18 & 0.74 & 4.21 & 4.21 & 0.74 \\
\hline $61 \beta$ & V & +1.534 & 13.47 & 13.47 & 4.38 & 4.38 & 11.26 & 8.43 & 8.43 & 11.26 \\
\hline $60 \beta$ & $\mathrm{O}$ & -1.626 & 20.16 & 20.16 & 8.13 & 8.13 & 12.72 & 0.40 & 0.40 & 12.72 \\
\hline $59 \beta$ & $\mathrm{O}$ & -1.764 & 6.75 & 6.75 & 0.28 & 0.28 & 14.27 & 8.52 & 8.52 & 14.27 \\
\hline $58 \beta$ & $\mathrm{O}$ & -2.428 & 24.09 & 24.09 & 10.35 & 10.35 & 5.73 & 0.46 & 0.46 & 5.73 \\
\hline
\end{tabular}

${ }^{a} \mathrm{~V}=$ virtual (unoccupied); $\mathrm{O}=$ occupied.

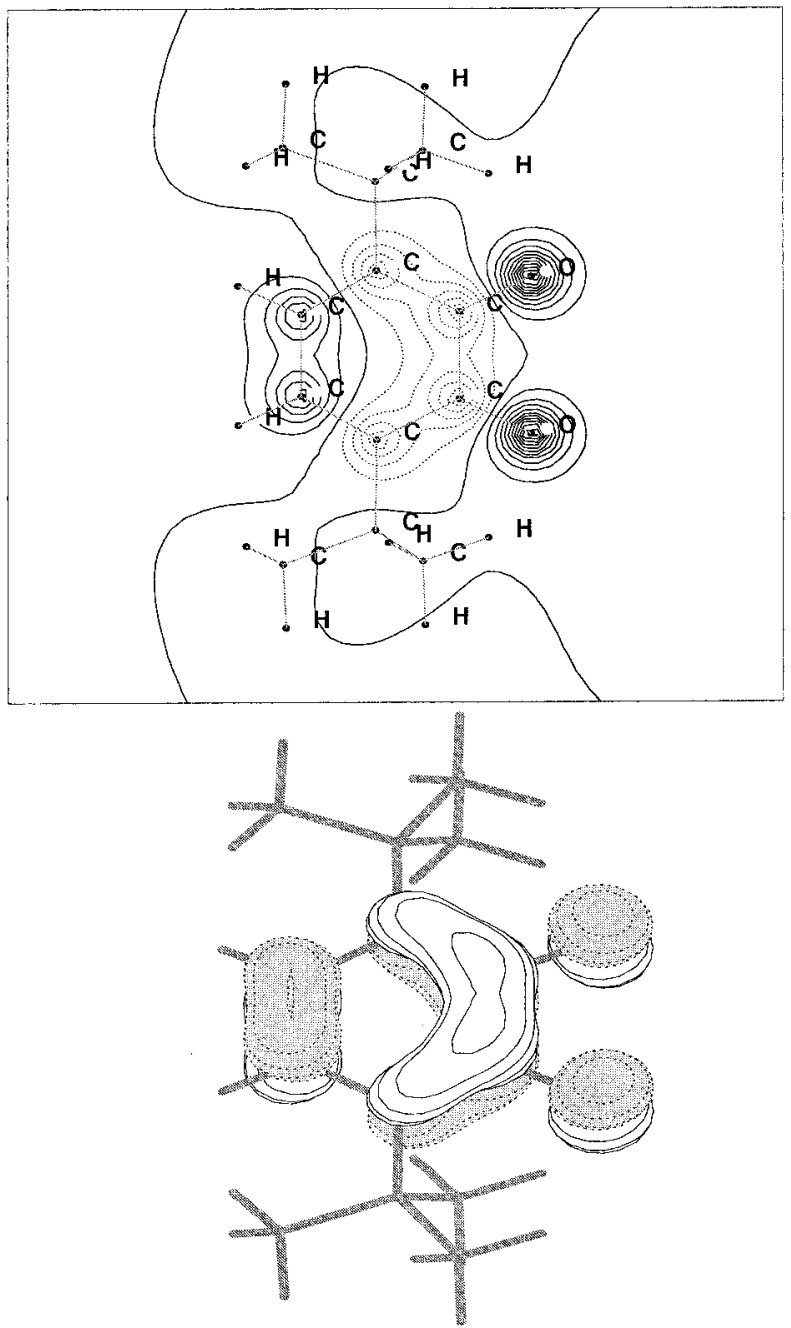

Figure 7. MO $61 \alpha$ of 3,6-di-tert-butylsemiquinone (HOMO). Top: Isovalue contour plot displaying the electron density obtained at the U-B3LYP/6-311G** level. The contour is a slice taken $0.5 \AA$ above the $x y$ plane and shows the $\pi$-antibonding interactions between the $\mathrm{C}\left(\mathrm{p}_{z}\right)$ and $\mathrm{O}\left(\mathrm{p}_{z}\right)$ orbitals and the $\pi$-bonding and $\pi$-antibonding interactions within the ring. Bottom: MO $61 \alpha$ of 3,6-DTBSQ. The orbital density is localized above and below the plane of the ring.

of the orbitals 58-62. Once again, the spatial distributions of the occupied MOs do not change upon reduction. However, we do find that the individual atomic contributions of some MOs exhibit subtle changes with respect to their 3,6-DTBSQ counterparts. Whereas reduction from 3,6-DTBQ to 3,6-DTBSQ was largely reflected in individual atomic contributions of the oxygen atoms, their relative contributions change little upon further reduction from semiquinone to catechol. Instead, some changes are observed throughout the ring but with no clear pattern. For example, in MO $61 \alpha$ of 3,6-DTBSQ O1 and O2 each contribute $14.32 \%$, while $\mathrm{C} 1$ and $\mathrm{C} 2$ each contribute $6.78 \%$. Upon reduction, $\mathrm{O} 1$ and $\mathrm{O} 2$ actually decrease in their contributions to $13.41 \%$ as do $\mathrm{C} 1$ and $\mathrm{C} 2$ (3.95\%). These shifts are offset by increases in contributions from C3 and C6. It is not immediately obvious why the more electronegative oxygens are not increasing their contributions more to the MO's of 3,6DTBCat to accommodate the electron. Part of the explanation may lie in the nearly aromatic nature of the catecholate molecule, which should allow for the additional electron density to be distributed around six carbon atoms as well as the oxygens. This is something not available to 3,6-DTBSQ, a nonaromatic species.

Despite the somewhat surprising shifts in atomic orbital contributions, the change in bond distances that occur upon reduction of 3,6-DTBSQ to 3,6-DTBCat are consistent with the bonding characteristics of MO $61 \beta$ of 3,6-DTBSQ. Upon reduction, bond distances increase for $\mathrm{C} 1-\mathrm{O} 1, \mathrm{C} 2-\mathrm{O} 2, \mathrm{C} 3-$ $\mathrm{C} 4$, and $\mathrm{C} 5-\mathrm{C} 6$, while the remaining bond distances decrease; these changes track the in-phase and out-of-phase atomic orbital combinations of the MO.

Energy Spacing of the Orbitals. Although a direct comparison of the absolute energies of orbitals across the redox series is not possible, we can examine how the relative energies of the orbitals in each molecule respond to changes in oxidation state. Table 7 lists the orbital energies for each molecule and the energy difference between each orbital $(\Delta E)$ for the three molecules in the 3,6 series.

In 3,6-DTBQ, orbital $58 \alpha$ lies $1.102 \mathrm{eV}$ below orbital $59 \alpha$. There is a smaller separation of $0.136 \mathrm{eV}$ between orbital $59 \alpha$ and the HOMO $(60 \alpha)$. The energy difference between MO $60 \alpha$ and $61 \alpha$ (HOMO-LUMO gap) is $3.230 \mathrm{eV}$ in 3,6-DTBQ. This is much larger than the $0.6 \mathrm{eV}$ HOMO-LUMO gap predicted by Bianchini et al. from an extended Hückel calculation. ${ }^{35}$

Upon reduction, we notice significant changes in the relative energy difference of the orbitals between 3,6-DTBQ and 3,6DTBSQ. In general, the occupied frontier orbitals are more densely packed, energetically, than in the case of the corresponding quinone. Orbital $58 \alpha$ is now only $0.374 \mathrm{eV}$ below $59 \alpha$, a ca. $70 \%$ reduction compared to 3,6-DTBQ. In contrast, the energy difference between orbitals $59 \alpha$ and $60 \alpha$ has increased slightly to $0.444 \mathrm{eV}$. MOs $60 \alpha$ and $61 \alpha$, which correspond to the HOMO-LUMO gap in 3,6-DTBQ, are separated by only $1.376 \mathrm{eV}$ as occupied MOs in 3,6-DTBSQ. The HOMO-LUMO gap of $1.950 \mathrm{eV}$ in 3,6-DTBSQ ( $61 \alpha$ and $61 \beta$ ) is substantially less than the corresponding gap in the quinone. This result is to be compared with the value of 0.520 $\mathrm{eV}$ we reported on the basis of the calculations using the BLYP functionals. ${ }^{31}$ The difference is likely due to the tendency of 
TABLE 6: Energies and Percent Atomic Contributions to the Frontier Molecular Orbitals of 3,6-DTBCat Obtained at the U-B3LYP/6-311G** Level

\begin{tabular}{cccrrrrrrrr}
\hline orbital $^{a}$ & type $^{b}$ & energy (eV) & \% O1 & \% O2 & \% C1 & \% C2 & \% C3 & \% C4 & \% C5 & \% C6 \\
\hline $62 \alpha, \beta$ & $\mathrm{V}$ & +7.161 & 0.13 & 0.13 & 0.16 & 0.16 & 0.94 & 1.74 & 1.74 & 0.94 \\
$61 \alpha, \beta$ & $\mathrm{O}$ & +4.466 & 13.41 & 13.41 & 3.95 & 3.95 & 10.67 & 7.64 & 7.64 & 10.67 \\
$60 \alpha, \beta$ & $\mathrm{O}$ & +3.146 & 20.49 & 20.49 & 7.28 & 7.28 & 12.43 & 0.39 & 0.39 & 12.43 \\
$59 \alpha, \beta$ & $\mathrm{O}$ & +2.763 & 7.46 & 7.46 & 0.13 & 0.13 & 13.58 & 6.96 & 6.96 & 13.58 \\
$58 \alpha, \beta$ & $\mathrm{O}$ & +2.541 & 24.21 & 24.21 & 8.74 & 8.74 & 6.24 & 0.33 & 0.33 & 6.24
\end{tabular}

${ }^{a}$ The $\alpha$ and $\beta$ orbitals for this closed-shell molecule were found to have identical compositions and are therefore listed jointly. ${ }^{b} \mathrm{~V}=$ virtual (unoccupied); $\mathrm{O}=$ occupied.

TABLE 7: Absolute and Relative Orbital Energies (in eV) for 3,6-DTBQ, 3,6-DTBSQ, and 3,6-DTBC at Calculated at the U-B3LYP/6-311G** Level

\begin{tabular}{lccc}
\hline \multicolumn{1}{c}{ orbital } & 3,6-DTBQ & $3,6-\mathrm{DTBSQ}$ & 3,6 -DTBCat \\
\hline $58 \alpha$ & -8.003 & Absolute Orbital Energies & +2.541 \\
$58 \beta$ & -8.003 & -2.610 & +2.541 \\
$59 \alpha$ & -6.901 & -2.428 & +2.763 \\
$59 \beta$ & -6.901 & -2.236 & +2.763 \\
$60 \alpha$ & -6.765 & -1.764 & +3.146 \\
$60 \beta$ & -6.765 & -1.792 & +3.146 \\
$61 \alpha$ & -3.535 & -1.626 & +4.466 \\
$61 \beta$ & -3.535 & -0.416 & +4.466 \\
$62 \alpha$ & -0.221 & +1.534 & +7.161 \\
$62 \beta$ & -0.221 & +4.097 & +7.161 \\
$58 \alpha-59 \alpha$ & & +4.101 & 0.222 \\
$59 \alpha-60 \alpha$ & 1.102 & Orbital Energy Differences & 0.383 \\
$60 \alpha-61 \alpha$ & 0.136 & 0.374 & 1.320 \\
$61 \alpha-61 \beta$ & 3.230 (HOMO-LUMO) & 0.444 & - \\
$61 \alpha-62 \alpha$ & - & 1.376 & 2.695 (HOMO-LUMO)
\end{tabular}

pure DFT methods (i.e. BLYP) to underestimate HOMOLUMO gaps relative to hybrid methods such as B3LYP that include Hartree-Fock exchange.

The addition of a second electron to form the catechol from the semiquinone does not have nearly as dramatic an impact on relative orbital energies as did the initial quinone to semiquinone reduction. The difference between orbital $58 \alpha$ and $59 \alpha$ is now $0.222 \mathrm{eV}$, substantially less than in 3,6-DTBQ but only ca. $0.15 \mathrm{eV}$ less than that found for 3,6-DTBSQ. In contrast, whereas the difference between orbitals $59 \alpha$ and $60 \alpha$ increased by ca. $0.3 \mathrm{eV}$ upon reduction of quinone to semiquinone, this difference was attenuated slightly upon further reduction to the catechol. The energy difference between the next pair of orbitals, $60 \alpha$ and $61 \alpha$, is $1.320 \mathrm{eV}$ : this is significantly smaller than the difference seen in 3,6-DTBQ (in that case corresponding to the HOMO-LUMO gap) but only slightly less than what was found for 3,6-DTBSQ. Finally, the HOMO-LUMO gap $(61 \alpha$ and $62 \alpha)$ of $2.695 \mathrm{eV}$ is ca. $0.7 \mathrm{eV}$ greater than the HOMO-LUMO of the semiquinone but still less than that calculated for the quinone.

Normal Population Analysis (NPA) Charge Densities. One aspect of these calculations we found interesting was how the charge distribution changes upon reduction. Table 8 lists the NPA charge densities obtained from calculations at the U-B3LYP/ $6-311 \mathrm{G}^{* *}$ level. We expected that most of the negative charge in the compound would be localized on the oxygen atoms due to their larger electronegativity and that this would likely increase with additional reducing equivalents. Table 8 shows that, in general, this is the case: in the neutral 3,6-DTBQ most of the negative charge resides on $\mathrm{O} 1$ and $\mathrm{O} 2$, with the magnitude of negative charge density increasing systematically through the semiquinone and catechol oxidation states. However, it should be noted that upon one electron reduction to 3,6-DTBSQ each oxygen atom becomes more negative by 0.16 while upon addition of a second electron each oxygen atom becomes more
TABLE 8: NPA Atomic Charge Densities Obtained for 3,6-DTBSQ, 3,6-DTBSQ, 3,5-DTBSQ, and 3,6-DTBCat at the U-B3LYP/6-311G** Level

\begin{tabular}{lcccc}
\hline & $3,6-D T B Q$ & $3,6-D T B S Q$ & $3,5-D T B S Q$ & $3,6-D T B C a t$ \\
\hline O1 & -0.496 & -0.655 & -0.626 & -0.833 \\
O2 & -0.496 & -0.655 & -0.662 & -0.833 \\
C1 & +0.475 & +0.371 & +0.368 & +0.343 \\
C2 & +0.475 & +0.371 & +0.362 & +0.343 \\
C3 & -0.073 & -0.121 & -0.113 & -0.217 \\
C4 & -0.164 & -0.238 & -0.257 & -0.303 \\
C5 & -0.164 & -0.238 & -0.066 & -0.303 \\
C6 & -0.073 & -0.121 & -0.306 & -0.217
\end{tabular}

negative by 0.18 . This implies that, upon reduction, there is strong delocalization of the additional negative charge over the carbons. However, not all of the carbon atoms possess negative charge density. Most of the positive charge in each oxidation state resides on $\mathrm{C} 1$ and $\mathrm{C} 2$, the carbons bound to the oxygens. Again, this is in line with expectations given the polarity of the $\mathrm{C}-\mathrm{O}$ bond. In 3,6-DTBQ, the remaining carbons have very little charge density, either positive or negative. Upon reduction we observe that, in general, all of the carbon atoms experience a net increase in negative charge. $\mathrm{C} 1$ and $\mathrm{C} 2$ still maintain a net positive charge density even in the catechol form, but $\mathrm{C} 3-\mathrm{C} 6$ show a systematic buildup of net negative charge density across the series. While the overall increase in the negative charge density at C3 and C6 versus C4 and C5 is approximately the same $(-0.144$ and -0.139 , respectively), the absolute charges of -0.217 (C3 and C6) and -0.303 (C4 and C5) indicate smaller net negative charge density at the substituted carbons. This most likely reflects the electron-donating properties of the alkyl substituents disfavoring the buildup of additional negative charge at these positions. Nevertheless, it does appear that substitution of the ring carbon atoms does have an effect on charge distribution within the molecule. 
TABLE 9: Energies and Percent Atomic Contributions to the Frontier Molecular Orbitals of 3,5-DTBSQ Obtained at the U-B3LYP/6-311G** Level

\begin{tabular}{cccrrrrrrrr}
\hline orbital & type $^{a}$ & energy (eV) & \% O1 & \% O2 & $\%$ C1 & \% C2 & \% C3 & \% C4 & \% C5 & $\%$ C6 \\
\hline $62 \alpha$ & $\mathrm{V}$ & +3.615 & 0.00 & 0.00 & 1.71 & 0.69 & 4.42 & 5.68 & 4.34 & 1.27 \\
$61 \alpha$ & $\mathrm{O}$ & -0.290 & 14.56 & 14.64 & 5.90 & 7.06 & 8.89 & 9.36 & 6.75 & 5.79 \\
$60 \alpha$ & $\mathrm{O}$ & -1.643 & 20.37 & 18.42 & 3.56 & 16.00 & 17.27 & 2.36 & 1.04 & 10.98 \\
$59 \alpha$ & $\mathrm{O}$ & -2.239 & 6.85 & 5.46 & 0.21 & 0.23 & 15.25 & 7.80 & 6.52 & 18.26 \\
$58 \alpha$ & $\mathrm{O}$ & -2.534 & 24.07 & 25.05 & 12.16 & 10.68 & 4.29 & 0.82 & 1.45 & 4.33 \\
$62 \beta$ & $\mathrm{V}$ & +3.618 & 0.00 & 0.00 & 1.71 & 0.68 & 4.17 & 5.60 & 4.36 & 1.27 \\
$61 \beta$ & $\mathrm{V}$ & +1.659 & 14.59 & 13.12 & 3.48 & 4.60 & 11.21 & 9.51 & 6.41 \\
$60 \beta$ & $\mathrm{O}$ & -1.470 & 20.95 & 17.94 & 3.47 & 16.36 & 17.05 & 2.36 & 1.05 & 11.06 \\
$59 \beta$ & $\mathrm{O}$ & -1.724 & 7.86 & 7.24 & 0.79 & 0.38 & 13.83 & 7.97 & 7.87 & 15.37 \\
$58 \beta$ & $\mathrm{O}$ & -2.349 & 23.29 & 25.51 & 12.57 & 10.71 & 4.54 & 0.84 & 1.46 & 4.23
\end{tabular}

${ }^{a} \mathrm{~V}=$ virtual (unoccupied); $\mathrm{O}=$ occupied.

\section{Substituent Effects}

It is a common practice in computational chemistry to make simplifications to molecules, for example substitution of a proton for a methyl group, to minimize computational cost. However, it is often unclear to what extent these types of substitutions influence the calculated properties of a molecule. Given this and the apparent sensitivity of atomic charge densities to ring substitution revealed by the analysis presented above, we have explored the issue of substituent effects by carrying out calculations on 3,5-di-tert-butylsemiquinone (3,5-DTBSQ), a structural isomer of 3,6-DTBSQ. The results provide us with insights into how the electronic structure of these molecules respond to changes in the pattern of ring substitution.

Geometric and Electronic Structure of 3,5-Di-tert-butylorthosemiquinone (3,5-DTBSQ). The optimized geometric parameters obtained after shifting a tert-butyl group from the 6 to the 5 position are presented in Table 2. We notice that, commensurate with the lower symmetry of the 3,5 isomer, the bond lengths of $\mathrm{C} 1-\mathrm{O} 1$ and $\mathrm{C} 2-\mathrm{O} 2$ are at 1.256 and $1.261 \AA$, respectively. This difference of $0.005 \AA$, although small, is in contrast to the equal bond lengths seen at all oxidation levels of the 3,6-DTB-quinoid molecules. The reduction in symmetry is seen in all of the metric details of the 3,5 isomer as compared to the 3,6 , reflecting loss of the $C_{2}$ axis through the $\mathrm{C} 1-\mathrm{C} 2$ bond. One consequence of these structural changes is a slight increase in the $\mathrm{O} 1-\mathrm{O} 2$ distance for the 3,5-DTBSQ isomer: in 3,5-DTBSQ this distance is $2.772 \AA$ whereas for 3,6-DTBSQ it decreases by ca. $0.06 \AA$ to $2.713 \AA$.

Table 9 lists the energies and composition of orbitals 58-62 obtained from a single-point calculation on 3,5-DTBSQ. As with the metric details outlined above, the lower symmetry of the 3,5 isomer is echoed in the atomic orbital coefficients of the molecular orbitals. A comparison of Table 5 with Table 9 shows that, whereas the MOs with respect to the molecular $C_{2}$ axis in terms of atomic contributions of 3,6-DTBSQ are symmetric, those of 3,5-DTBSQ reflect the $\mathrm{C}_{1}$ symmetry of the molecule. For example, in MO $60 \alpha$ O1 makes a contribution of $20.37 \%$ while $\mathrm{O} 2$ contributes $18.42 \%$; in 3,6-DTBSQ, each oxygen had an equivalent contribution of $20.03 \%$. A similar lack of symmetry is observed in the atomic contributions from the carbon atoms of the ring.

Although details of the orbital composition of 3,5-DTBSQ differ somewhat from those of 3,6-DTBSQ, a comparison of Figure 7 with Figure 8 reveals that the HOMOs for each molecule are qualitatively similar. The greatest contribution to the HOMO in both cases is from the oxygen atoms, each contributing in the range of $14-15 \%$. The carbon atoms all show roughly equivalent contributions in the range of $6-9 \%$. Thus,
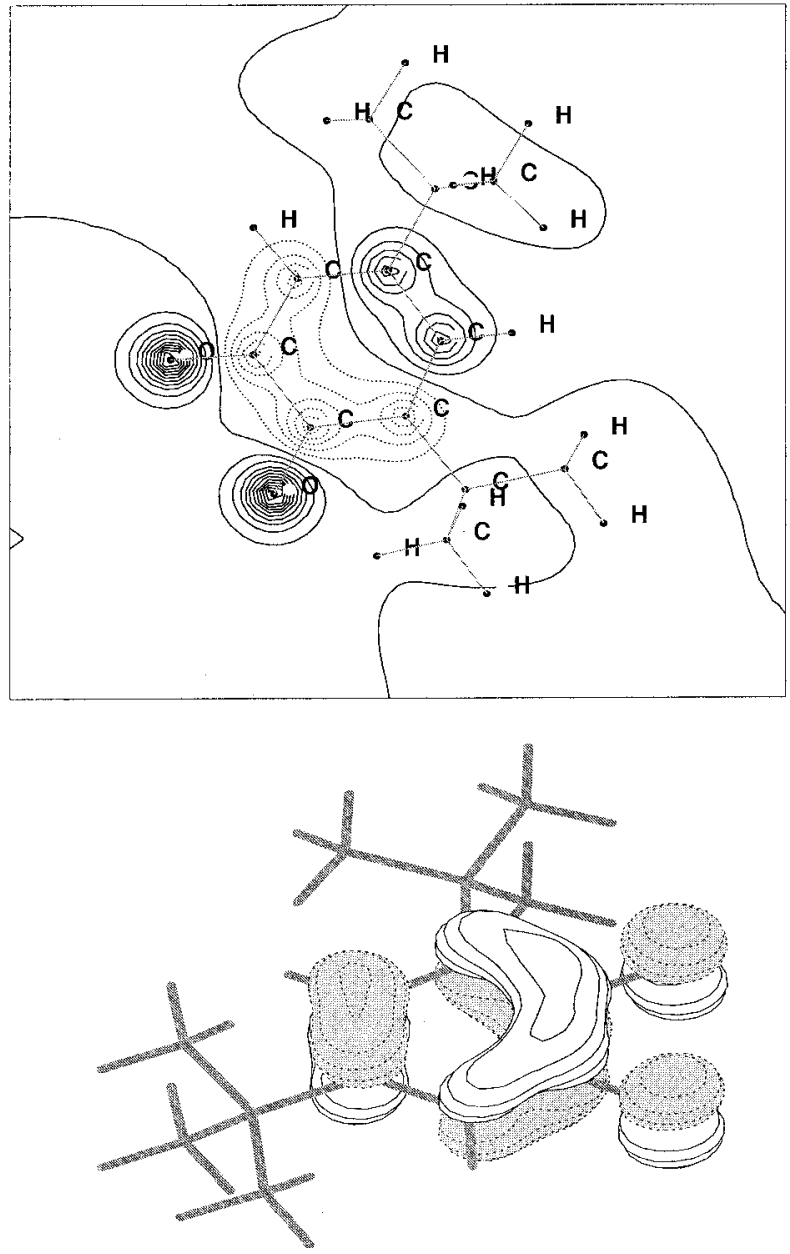

Figure 8. MO $61 \alpha$ of 3,5-di-tert-butylsemiquinone (HOMO). Top: Isovalue contour plot displaying the electron density obtained at the U-B3LYP/6-311G** level. The contour is a slice taken $0.5 \AA$ above the $x y$ plane and shows the $\pi$-antibonding interactions between the $\mathrm{C}\left(\mathrm{p}_{z}\right)$ and $\mathrm{O}\left(\mathrm{p}_{z}\right)$ orbitals and the $\pi$-bonding and $\pi$-antibonding interactions within the ring. Bottom: MO $61 \alpha$ of 3,5-DTBSQ. The orbital density is localized above and below the plane of the ring

it does not appear that repositioning of the tert-butyl group has a significant impact on the spatial distribution of the molecular orbitals.

Orbital Energies and Spin and Charge Distributions. Unlike orbital energies across the 3,6-DTBQ redox series, where the total electron count varied, the fact that 3,5-DTBSQ and 3,6-DTBSQ are geometric isomers allows us to make direct comparisons among orbital energies for these compounds. Figure 9 shows the relative energies of orbitals 58-62 for 3,5-DTBSQ and 3,6-DTBSQ. The orbitals of 3,5-DTBSQ are generally found 


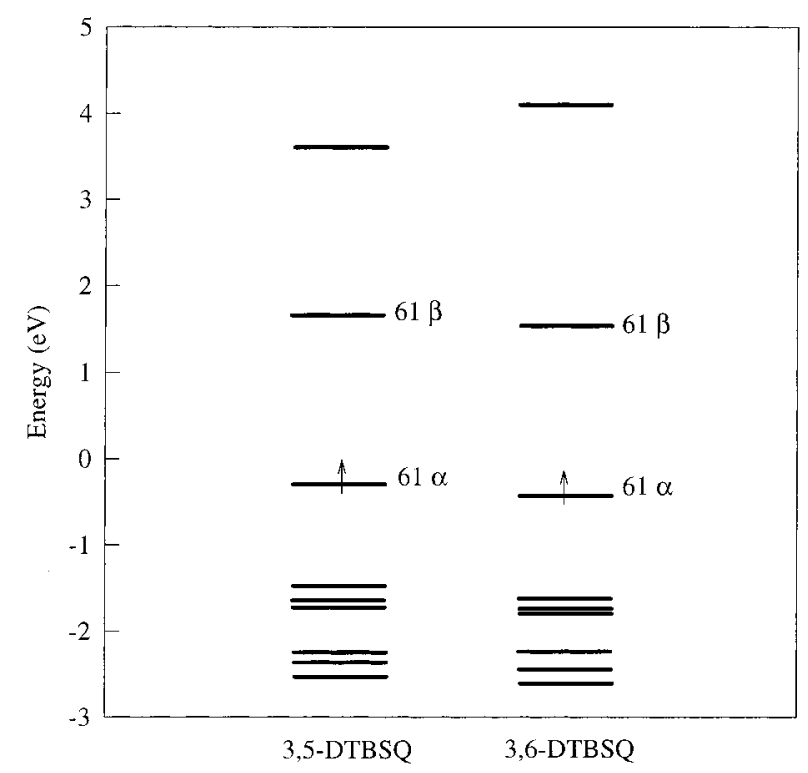

Figure 9. Relative energies of orbitals 58-62 for 3,5-DTBSQ and 3,6-DTBSQ from calculations performed at the U-B3LYP/6-311G** level.

to be higher in energy than the corresponding orbitals of 3,6DTBSQ. Focusing only on the HOMO of each compound (61 $\alpha$ ), we find that the movement of a tert-butyl group from the 6 position to the 5 position causes the energy of the HOMO to increase by $0.126 \mathrm{eV}$. We had initially thought the difference in energy between the two molecules might be related to steric interations between the tert-butyl groups and the oxygen atoms. However, if this were the origin of the energy shift, we would have expected the HOMO for 3,6-DTBSQ to be higher in energy.

Table 8 shows the NPA charge Densities for 3,5-DTBSQ and 3,6-DTBSQ. As was the case with 3,6-DTBSQ, the greatest negative charge in 3,5-DTBSQ resides on O1 and O2. Significant positive charge density is found on $\mathrm{C} 1$ and $\mathrm{C} 2$, although slightly smaller in magnitude than that observed in the 3,6 isomer. In general, the charge distribution for 3,5-DTBSQ exhibits roughly the same pattern throughout the ring as was found in 3,6-DTBSQ. The carbon atoms substituted with a tertbutyl group exhibit less negative charge then the unsubstituted carbons. For example, in 3,6-DTBSQ the two carbons to which the tert-butyl groups are bound (i.e. C3 and C6) exhibit a negative charge density of -0.121 each. $\mathrm{C} 4$ and $\mathrm{C} 5$, which are the less substituted ring carbons, show a slightly larger net charge of -0.238 . We find that, for the 3,5 isomer, the largest negative charge density in the ring is found on $\mathrm{C} 4$ and $\mathrm{C} 6$, the less substituted ring carbons, while $\mathrm{C} 3$ and $\mathrm{C} 5$ exhibit charges of -0.113 and -0.066 , respectively. Clearly, the charge density is tracking the movement of the tert-butyl group.

Finally, we wanted to examine the Mulliken spin densities to see if any trends could be found on going from 3,6-DTBSQ to 3,5-DTBSQ. Table 10 lists the Mulliken spin densities for 3,5-DTBSQ and 3,6-DTBSQ. We find that in 3,6-DTBSQ most of the spin density is located on $\mathrm{O} 1$ and $\mathrm{O} 2$, as was found in our previous study. The carbon atoms of the ring share the remaining spin density approximately equally with values of ca. +0.1 , except for $\mathrm{C} 1$ and $\mathrm{C} 2$, which have slightly less spin density at +0.06 . Some similar trends are seen for the spin distribution of 3,5-DTBSQ. Most of the spin density in the molecule is located on the oxygen atoms with $\mathrm{O} 1$ and $\mathrm{O} 2$ having values of +0.271 and +0.245 , respectively. However, we find a much larger variation in spin density throughout the ring than
TABLE 10: Mulliken Net Spin Densities and NPA Atomic Spin Densities for 3,5-DTBSQ and 3,6-DTBSQ from Calculations Peformed Using the U-B3LYP Functional at the 6-311G**Level

\begin{tabular}{lcccc}
\hline & $3,5-\mathrm{DTBSQ}^{a}$ & $3,5-\mathrm{DTBSQ}^{b}$ & $3,6-\mathrm{DTBSQ}^{a}$ & $3,6-\mathrm{DTBSQ}^{b}$ \\
\hline $\mathrm{O} 1$ & +0.271 & +0.272 & +0.252 & +0.255 \\
$\mathrm{O} 2$ & +0.245 & +0.248 & +0.252 & +0.255 \\
$\mathrm{C} 1$ & +0.031 & +0.038 & +0.066 & +0.068 \\
$\mathrm{C} 2$ & +0.075 & +0.076 & +0.066 & +0.068 \\
$\mathrm{C} 3$ & +0.095 & +0.087 & +0.097 & +0.088 \\
$\mathrm{C} 4$ & +0.116 & +0.104 & +0.099 & +0.088 \\
$\mathrm{C} 5$ & +0.072 & +0.075 & +0.099 & +0.088 \\
C6 & +0.111 & +0.098 & +0.097 & +0.088
\end{tabular}

${ }^{a}$ Mulliken spin densities. ${ }^{b}$ NPA atomic spin densities.

is seen for 3,6-DTBSQ. It appears as though the carbons attached to the tert-butyl groups have less spin density then those attached to hydrogens; i.e., C3 and C5 have values of +0.095 and +0.072 , respectively, versus $\mathrm{C} 4$ and C6 with values of +0.116 and +0.111 , respectively. Corresponding differences between the tert-butyl substituted carbons and the hydrogen substituted carbons was only +0.002 spin units for 3,6-DTBSQ.

\section{Concluding Comments}

We have applied nonlocal gradient-corrected density functional theory to the study of a complete redox series within the quinone family of molecules. Specifically, orthoquinones, which are of use in transition metal chemistry for the preparation of exchange-coupled and valence tautomeric molecules, have been analyzed in terms of geometric and electronic structure variations that accompany changes in the redox state of the ligand. Some of the principal results we have obtained are summarized below.

(1) A comparison of the optimized geometry of 1,2-benzoquinone with available X-ray crystallographic data ${ }^{44}$ reveal that the optimization at the U-B3LYP/6-31G* level yielded a structure that is nearly indistinguishable from that obtained experimentally. This gives added confidence that structures obtained on other compounds in this study for which X-ray data are not available are likely to be highly accurate representations of their true geometries.

(2) For the 3,6-di-tert-butyl quinoids, structural changes that accompany addition of each electron from quinone to semiquinone to catechol are consistent with expectations from simple resonance pictures of these molecules. Specifically, it is found that the $\mathrm{C}-\mathrm{O}$ bond distances increase from that characteristic of a double bond (quinone) to a single bond (catechol), with the semiquinone lying roughly between these two extremes. Metric details within the ring are observed to become more or less equivalent as the (nearly) aromatic nature of the catechol is approached across the series.

(3) The differences between the molecular orbital compositions of some moleuclar orbitals are subtle but nevertheless significant. For example, the HOMO of 3,6-DTBSQ (MO 61 $\alpha$ ) closely resembles MOs $61 \alpha, \beta$ of 3,6-DTBQ whereas its LUMO (MO $61 \beta$ ) closely resembles MOs $61 \alpha, \beta$ of 3,6-DTBCat. In general, however, the basic qualitative description of the MOs across the series is fairly similar. Thus the Aufbau principal applied to the quinone molecular orbital scheme provides a reasonable picture of the electronic structure of each member of the redox series.

(4) While the overall ordering of the molecular orbitals is not sensitive to the addition of electrons, the relative and absolute energies of the orbitals do shift significantly with changes in oxidation state. It is found that the HOMO-LUMO 
gap is smallest for 3,6-DTBSQ at $1.950 \mathrm{eV}$, followed by 3,6DTBCat at $2.695 \mathrm{eV}$, and finally the quinone form at 3.230 $\mathrm{eV}$.

(5) NPA charge densities reveal that electronegativity differences appear to dominate localization of net charge within the molecule, with the oxygen atoms showing the largest increase in negative charge upon reduction from quinone to semiquinone.

(6) Unpaired spin density in the paramagnetic 3,6-DTBSQ is largely localized on the oxygen atoms. Significantly smaller but nonzero amounts of net $\alpha$ spin density are also found on the carbon atoms of the ring.

(7) Calculations carried out on 3,5-DTBSQ, a structural isomer of 3,6-DTBSQ, indicate small but nonetheless discernible differences in absolute orbital energies, NPA charge densities, and unpaired spin densities upon changing the substitution pattern of the ring. Although some of the differences clearly arise due to the reduction in symmetry, others have a less obvious origin.

This final point, concerning the changes noted in the electronic structure of the semiquinone upon shifting the tertbutyl group from the 6-position to the 5-position, is one of the more intriguing results we obtained from this work. As indicated at the beginning of the Electronic Structure of Quinoids section, compositional simplification of molecules is a common practice in quantum chemistry. Indeed, such an approach is clearly necessary for many systems in order to make theoretical work on them feasible. However, it is difficult to know what effect these simplifications have on the calculations and therefore the conclusions derived from them relative to the actual chemical system being modeled. In the present study, the change we have induced in our chemical system is a fairly minor one-much less drastic than replacing a tert-butyl group with a hydrogen atom, for example-yet changes in the electronic structure of the compound are observed.

It is difficult to say whether differences of the magnitude noted for 3,6-DTBSQ versus 3,5-DTBSQ are chemically significant. However, it is known experimentally that the electronic structure of transition metal complexes containing 3,6-DTBSQ as a ligand(s) are surprisingly different from those containing 3,5-DTBSQ. These conclusions derive largely from variable-temperature magnetic susceptibility data, where the metal-ligand interaction can be quantified by use of the Heisenberg spin Hamiltonian of the form $\mathbf{H}=J_{i j} \cdot \mathbf{S}_{i} \cdot \mathbf{S}_{j}$. In this equation, $\mathbf{S}_{i}$ and $\mathbf{S}_{j}$ are single-ion spin operators and $J_{i j}$ is an electron exchange integral, which in the present case gauges the magnitude of electronic coupling between the paramagnetic metal center $\left(\mathbf{S}_{i}\right)$ and the semiquinone ligand bound to it $\left(\mathbf{S}_{j}\right)$. Data collected in our laboratory ${ }^{45}$ and others ${ }^{46}$ clearly indicate that electron exchange is stronger for a given metal interacting with 3,5-DTBSQ than with 3,6-DTBSQ. Given this experimental result, it is interesting to note from our calculations that movement of the tert-butyl group from the 6-position to the 5 -position results in an increase in the energy of MO $61 \alpha$, the HOMO for the free ligand. With the likelihood that, prior to orbital mixing, the occupied d-orbitals of the transition metal are higher in energy than any occupied orbital of the organic ligand, the increase in energy of the 3,5-DTBSQ HOMO relative to 3,6-DTBSQ would be consistent with a stronger spin exchange interaction. In other words, an increase in the HOMO energy of the ligand would, in the limit of all other factors being constant, result in a better energetic match between the ligand and metal orbitals and hence a larger value of $J_{i j}$. It should be stressed, however, that the caveat of all other factors being constant is an important one: the magnitude of Heisenberg spin exchange is sensitive to a number of variables, not the least of which is geometry. While the shift in energy of the HOMO from 3,6-DTBSQ to 3,5-DTBSQ is consistent with an increase in $J_{i j}$, it is only one of several factors that would need to be considered before a direct link between the electronic structures described herein and Heisenberg exchange in metal complexes containing these ligands could be made.

Acknowledgment. This work was supported through funds from the National Science Foundation (Grant CHE-9729003) and the Alfred P. Sloan Foundation (J.K.M.). Calculations were made possible through allocation grants from the National Center for Supercomputer Applications (NCSA).

\section{References and Notes} 1974

(1) The Chemistry of the Quinonoid Compounds; Wiley: New York,

(2) Trumpower, B. L. Functions of Quinones in Energy Converting Systems; Trumpower, B. L., Ed.; Academic: New York, 1982.

(3) Okamura, M. Y.; Feher, G. Annu. Rev. Biochem. 1992, 61, 881.

(4) Klinman, J. P.; David, M. Annu. Rev. Biochem. 1994, 63, 299.

(5) Ding, H.; Moser, C. C.; Robertson, D. E.; Tokito, M. K.; Daldal, F.; Duttion, P. L. Biochemistry 1995, 34, 11606.

(6) Ayscough, P. B. Electron Spin Resonance in Chemistry; Methuen \& Co. Ltd: London, 1974

(7) Broze, M.; Luz, Z.; Silver, B. L. J. Chem. Phys. 1967, 46, 4891.

(8) Dixon, W. T.; Murphy, D. J. J. Chem. Soc., Faraday Trans. 1972, 72,1221 .

(9) Hales, B. J. J. Am. Chem. Soc. 1975, 97, 5993

(10) Hales, B. J. J. Am. Chem. Soc. 1976, 98, 7350.

(11) Neta, P.; Fessenden, W. J. Phys. Chem. 1974, 78, 523.

(12) Niethammer, D.; Kirste, B.; Kurreck, H. J. Chem. Soc., Faraday Trans. 1990, 86, 3191.

(13) O’Malley, P. J.; Babcock, G. T. J. Am. Chem. Soc. 1986, 108, 3995

(14) Sullivan, P. D.; Bolton, J. R.; Geiger, W. E., Jr. J. Am. Chem. Soc. 1970, 92, 4176

(15) Eriksson, L. A.; Himo, F.; Siegbahn, P. E. M.; Babcock, G. T. J. Phys. Chem. A 1997, 101, 9496.

(16) Mohandas, P.; Umapathy, S. J. Phys. Chem. A 1997, 101, 4449

(17) Zhan, C.-G.; Iwata, S. Chem. Phys. 1998, 230, 45.

(18) Nonella, M. J. Phys. Chem. B 1997, 101, 1235

(19) Chipman, D. M.; Prebenda, M. F. J. Phys. Chem. 1986, 90, 5557.

(20) Raymond, K. S.; Wheeler, R. A. J. Chem. Soc., Faraday Trans. 1993, 89, 665 .

(21) Wise, K. E.; Grafton, A. K.; Wheeler, R. A. J. Phys. Chem. 1997, 101,1160

(22) Boesch, S. E.; Wheeler, R. A. J. Phys. Chem. 1995, 99, 8125

(23) Pople, J. A.; Beveridge, D. L.; Dobosh, P. A. J. Am. Chem. Soc. 1968, 90, 4201.

(24) O'Malley, P. J.; Collins, S. J. Chem. Phys. Lett. 1996, 259, 296

(25) Datta, S. N.; Mallik, B. Int. J. Quantum Chem. 1997, 61, 865.

(26) Boesch, S. E.; Grafton, A. K.; Wheeler, R. A. J. Phys. Chem. 1996, 100,10083 .

(27) Wheeler, R. A. J. Am. Chem. Soc. 1994, 116, 11048.

(29) Pierpont, C. G.; Larsen, S. K.; Boone, S. R. Pure Appl. Chem. 1988, 60, 1331

(30) Pierpont, C. G.; Lange, C. W. Prog. Inorg. Chem. 1994, 41, 331

(31) Rodriguez, J. H.; Wheeler, D. E.; McCusker, J. K. J. Am. Chem. Soc. 1998, 120, 12051

(32) Adams, D. M.; Noodleman, L.; Hendrickson, D. N. Inorg. Chem. 1997, 36, 3966.

(33) Bencini, A.; Ciofini, I.; Giannasi, E.; Daul, C. A.; Doclo, K. Inorg. Chem. 1998, 37, 3719.

(34) Gordon, D. J.; Fenske, R. F. Inorg. Chem. 1982, 21, 2908.

(35) Bianchini, C.; Masi, D.; Mealli, C.; Meli, A.; Martini, G.; Laschi, F.; Zanello, P. Inorg. Chem. 1987, 26, 3683.

(36) Frisch, M. J.; Trucks, G. W.; Schlegel, H. B.; Gill, P. M. W.; Johnson, B. G.; Robb, M. A.; Cheeseman, J. R.; Keith, T.; Petersson, G. A.; Montgomery, J. A.; Raghavachari, K.; Al-Laham, M. A.; Zakrzewski, V. G.; Ortiz, J. V.; Foresman, J. B.; Cioslowski, J.; Stefanov, B. B.; Nanayakkara, A.; Challacombe, M.; Peng, C. Y.; Ayala, P. Y.; Chen, W.; Wong, M. W.; Andres, J. L.; Replogle, E. S.; Gomperts, R.; Martin, R. L.; Fox, D. J.; Binkley, J. S.; Defrees, D. J.; Baker, J.; Stewart, J. P.; HeadGordon, M.; Gonzalez, C.; Pople, J. A. Gaussian 94, revision E.2; Gaussian, Inc.: Pittsburgh, PA, 1995 
(37) Frisch, M. J.; Trucks, G. W.; Schlegel, H. B.; Scuseria, G. E.; Robb, M. A.; Cheeseman, J. R.; Zakrzewski, V. G.; Montgomery, J. A., Jr.; Stratmann, R. E.; Burant, J. C.; Dapprich, S.; Millam, J. M.; Daniels, A. D.; Kudin, K. N.; Strain, M. C.; Farkas, O.; Tomasi, J.; Barone, V.; Cossi, M.; Cammi, R.; Mennucci, B.; Pomelli, C.; Adamo, C.; Clifford, S.; Ochterski, J.; Petersson, G. A.; Ayala, P. Y.; Cui, Q.; Morokuma, K.; Malick, D. K.; Rabuck, A. D.; Raghavachari, K.; Foresman, J. B.; Cioslowski, J.; Ortiz, J. V.; Stefanov, B. B.; Liu, G.; Liashenko, A.; Piskorz, P.; Komaromi, I.; Gomperts, R.; Martin, R. L.; Fox, D. J.; Keith, T.; Al-Laham, M. A.; Peng, C. Y.; Nanayakkara, A.; Gonzalez, C.; Challacombe, M.; Gill, P. M. W.; Johnson, B.; Chen, W.; Wong, M. W.; Andres, J. L.; Gonzalez, C.; Head-Gordon, M.; Replogle, E. S.; Pople, J. A. Gaussian 98, revision A.4; Gaussian, Inc.: Pittsburgh, PA, 1998

(38) Lee, C.; Yang, W.; Parr, R. G. Phys. Rev. B 1988, 37, 785.

(39) Becke, A. D. Phys. Rev. A 1988, 38, 3098.

(40) Becke, A. D. J. Chem. Phys. 1993, 98, 1372.
(41) Becke, A. D. J. Chem. Phys. 1993, 98, 5648.

(42) Frisch, M. J.; Frisch, A.; Foresmann, J. B. Gaussian 94 User's Manual; Gaussian, Inc.: Pittsburgh, 1995.

(43) SPARTAN, 4.0 ed.; Wavefunction, Inc.: Irvine, CA, 1995.

(44) Macdonald, A. L.; Trotter, J. J. Chem. Soc., Perkin Trans. 2 1973, 473.

(45) Wheeler, D. E.; McCusker, J. K. Unpublished results.

(46) Attia, A. S.; Conklin, B. J.; Lange, C. W.; Pierpont, C. G. Inorg. Chem. 1996, 35, 1033.

(47) Reed, A. E.; Wienhold, R. J. Chem. Phys. 1983, 78, 4066.

(48) Reed, A. E.; Weinstock, R. B.; Weinhold, F. J. Chem. Phys. 1985, 83,735 .

(49) Glendening, E. D.; Reed, A. E.; Carpenter, J. E.; Weinhold, F. NBO 3.1, Theoretical Chemistry Institute, University of Wisconsin: Madison, WI, 1996. 